\title{
High-Temperature Superconducting Fiber
}

\author{
Daniel Homa · Yongxuan Liang • Gary Pickrell
}

Received: 6 January 2014 / Accepted: 15 January 2014 / Published online: 29 January 2014

(C) The Author(s) 2014. This article is published with open access at Springerlink.com

\begin{abstract}
In this study, we demonstrated superconductivity in a fiber with an yttrium barium copper oxide core and fused silica cladding. The fibers were fabricated via a modified melt-draw technique and post-process annealing treatment in excess oxygen. The fibers maintained overall diameters ranging from 100-900 microns and core diameters of 50-700 microns. Superconductivity of this fiber design was validated via the traditional four-point probe test method in a bath of liquid nitrogen at temperatures on the order of $93 \mathrm{~K}$. The high-temperature superconducting fiber provides a glimpse of its cross cutting potential in fields of electromagnetism, healthcare, optics, and energy and lends credence to the promise for superconductivity.
\end{abstract}

Keywords Superconductivity - Superconductor cables . Fiber optics · Optical fiber · High-temperature superconductors

The promise of superconductivity continues to cultivate a sustained and intense interest from the scientific community because of the inverse relationship between finite sources of energy and the demands of a growing industrialized global community. Superconductivity is an inherent solution to the challenges of electric power transmission, transportation, and magnetic energy storage [1]. Since its discovery in 1911, the extremely low transition temperatures often relegated the use of superconductivity to the laboratory because of the expense and difficulties associated with the use of liquid helium [2]. The trajectory of research and developments in

D. Homa $(\varangle) \cdot$ Y. Liang $\cdot$ G. Pickrell

Virginia Polytechnic Institute and State University, 213 Holden

Hall, Blacksburg, VA, 24060, USA

e-mail: dan24@vt.edu

url: www.mse.vt.edu the field of superconductivity appeared to change in 1987 upon the discovery of "high-temperature" superconductivity in YBCO because of the higher transition temperatures, 93 $\mathrm{K}$, that allowed the use of a much more cost effective cryogen: liquid nitrogen $[3,4]$ Although the pursuit of "roomtemperature" superconductivity continues, significant effort has been dedicated to improved cable designs and manufacturing processes for these basic high-temperature superconductors [5,6]. Although the pioneering work over the past few decades has made superconductivity relevant in an increasing number of applications, superconductivity has yet to experience the revolution seen with semiconductors and fiber optics [7-9]. The lack of traditional cable structures has, in part, impeded mass commercialization.

To meet this need, superconductivity was demonstrated in a lead core fiber via a multidisciplinary approach akin to current research dedicated to the integration of semiconductor devices into optical fibers [10-12]. Unfortunately, the extremely low transition temperature, $T_{\mathrm{c}} \approx 7.2 \mathrm{~K}$, of lead necessitated the use of liquid helium, which is both expensive and difficult to handle. Thus, a superconducting fiber with a high-temperature superconducting core material such as yttrium barium copper oxide is preferable for the majority of applications.

In this letter, we demonstrate a high-temperature Type II superconducting fiber, as seen in Fig. 1. The yttrium barium copper oxide core of these types of fibers exhibited zero resistance at temperatures of approximately $93 \mathrm{~K}$.

The superconducting core fibers were prepared by the melt-draw technique on a traditional glass working lathe, as seen in Fig. 2 [10, 13]. First, a fused silica substrate tube (GE214, OD $=8 \mathrm{~mm}, \mathrm{ID}=3 \mathrm{~mm}$ ) was fused to a processing tube $(\mathrm{GE} 214, \mathrm{OD}=9.5 \mathrm{~mm}, \mathrm{ID}=7 \mathrm{~mm})$. A smaller diameter fused silica rod (GE214, $8 \mathrm{~mm}$ ) was used to push the yttrium barium copper oxide melt into the substrate tube 


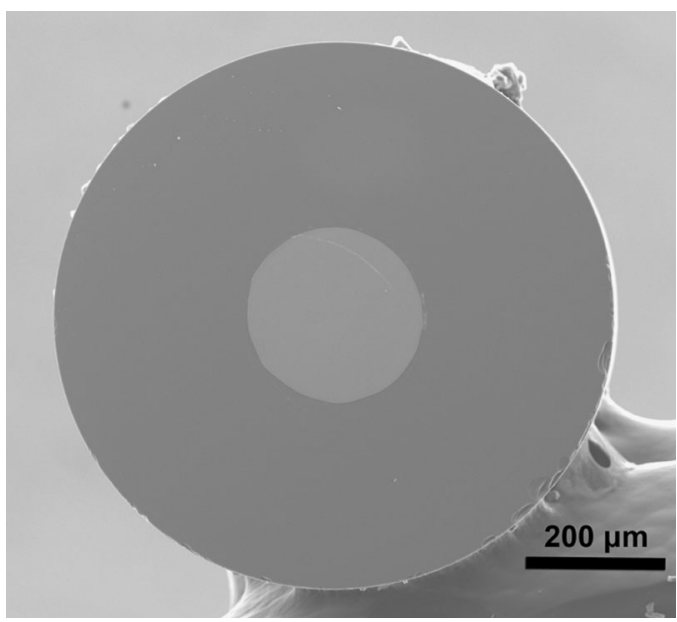

Fig. 1 SEM image of superconducting fiber with a $200 \mu \mathrm{m}$ yttrium barium oxide copper oxide core and fused silica cladding with an overall diameter of $800 \mu \mathrm{m}$

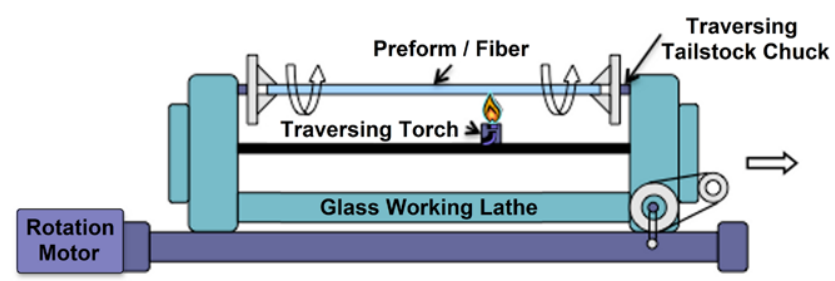

Fig. 2 Schematic of the custom fiber drawing system utilized to fabricate the high-temperature superconducting core fibers

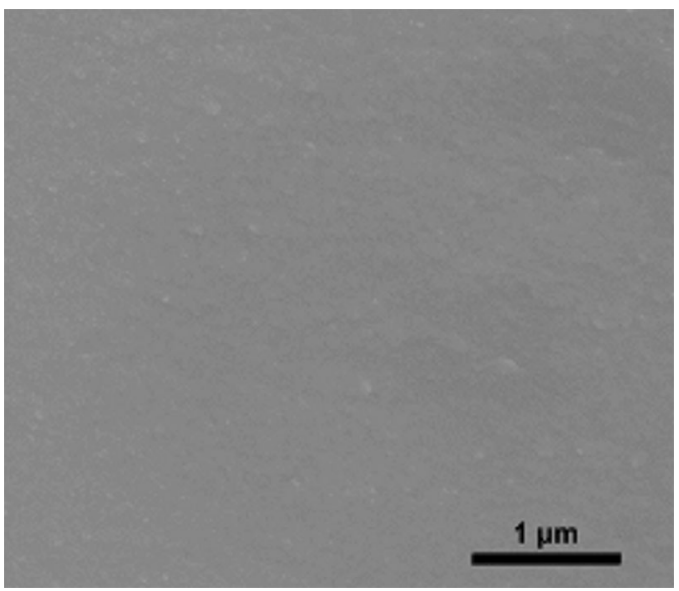

Fig. 3 SEM image of the yttrium barium copper oxide core with minimal or no evident porosity (magnification bar of $1 \mu \mathrm{m}$ for reference)

forming a preform with a YBCO core. Finally, the preform was drawn into a fiber via a technique similar to the Taylor process $[14,15]$.

The drawing temperature required for fused silica based optical fibers was on the order of $2000-2100{ }^{\circ} \mathrm{C}$, which is much higher than the melting point of $\mathrm{YBCO}\left(\sim 1010^{\circ} \mathrm{C}\right)$ [16]. As shown in Fig. 3, the rapid consolidation of the core melt upon fiberization produced a YBCO core with minimal porosity. However, the as-drawn YBCO core fibers were essentially nonsuperconducting due high-temperature phase separation, loss of oxygen upon relatively rapid cooling, possible silicon diffusion from the cladding, and thermal decomposition [17]. Thus, the as-drawn fiber was annealed in an oxygen rich environment to recover it to superconductive state. Generally, the YBCO core fibers were heated to $950{ }^{\circ} \mathrm{C}$, at a rate of $5{ }^{\circ} \mathrm{C} / \mathrm{min}$, and held at this temperature for a period of for 12 hours, cooled to $500{ }^{\circ} \mathrm{C}$ at a rate of $1{ }^{\circ} \mathrm{C} / \mathrm{min}$ and held for 12 hours, and then allowed to naturally cool to room temperature $[18,19]$.

The fibers were fabricated on a glass working lathe, Litton Model HSJ143. The maximum achievable fiber lengths were limited by the working distance, approximately 1.2 meters, between the chuck faces, the preform length and draw rod at the tailstock end. Fiber diameters in the range of 100-900 microns were routinely fabricated to maximum lengths of 1.2 meters. Fiberization via the glass working lathe allows for the preliminary determination of feasibility prior to process implementation on a more traditional fiber drawing tower. The fundamental techniques are based on the Taylor and Taylor-Ulitovsky methods, which are employed to manufacture fiber lengths on the order of kilometers [20-24].

Polished fiber cross sections were characterized with a scanning electron microscope (SEM, LEO 1550). As shown previously in Fig. 1, the superconducting fiber possessed impressive core/clad concentricity and a distinct interface between the YBCO core and the fused silica glass cladding. The fused silica cladding maintained a diameter of approximately $800 \mu \mathrm{m}$ and YBCO core diameter of $250 \mu \mathrm{m}$, respectively. Energy dispersive spectroscopy (EDS) chemical composition and mapping were performed with an attached IXRF system, Inc Iridium Microanalysis System, at an accelerating voltage of $20.0 \mathrm{kV}$. The EDS mapping images at the core-cladding interface can be seen in Fig. 4. A distinct transition between the cladding, $\mathrm{SiO}_{2}$, and the core, YBCO, exists at the interface, although cross diffusion of both yttrium and barium is evident. Preliminary EDS chemical composition analysis suggested a Y:Ba:Cu elemental ratio of approximately 1:1.96:2.57, but further investigation is required to minimize the potential measurement artifacts caused by silicon and silicon dioxide contamination of the core material upon sample preparation and analysis and the characterization methods.

The superconductivity of the YBCO core fibers was verified via the four-probe test method as shown in Fig. 5 [25]. The effects of contact resistance are eliminated via the fourprobe test method. Resistance to the flow of electrical current will produce a voltage drop measured between the two voltage probes. Conversely, a superconductor will exhibit no voltage drop below the critical temperature. 

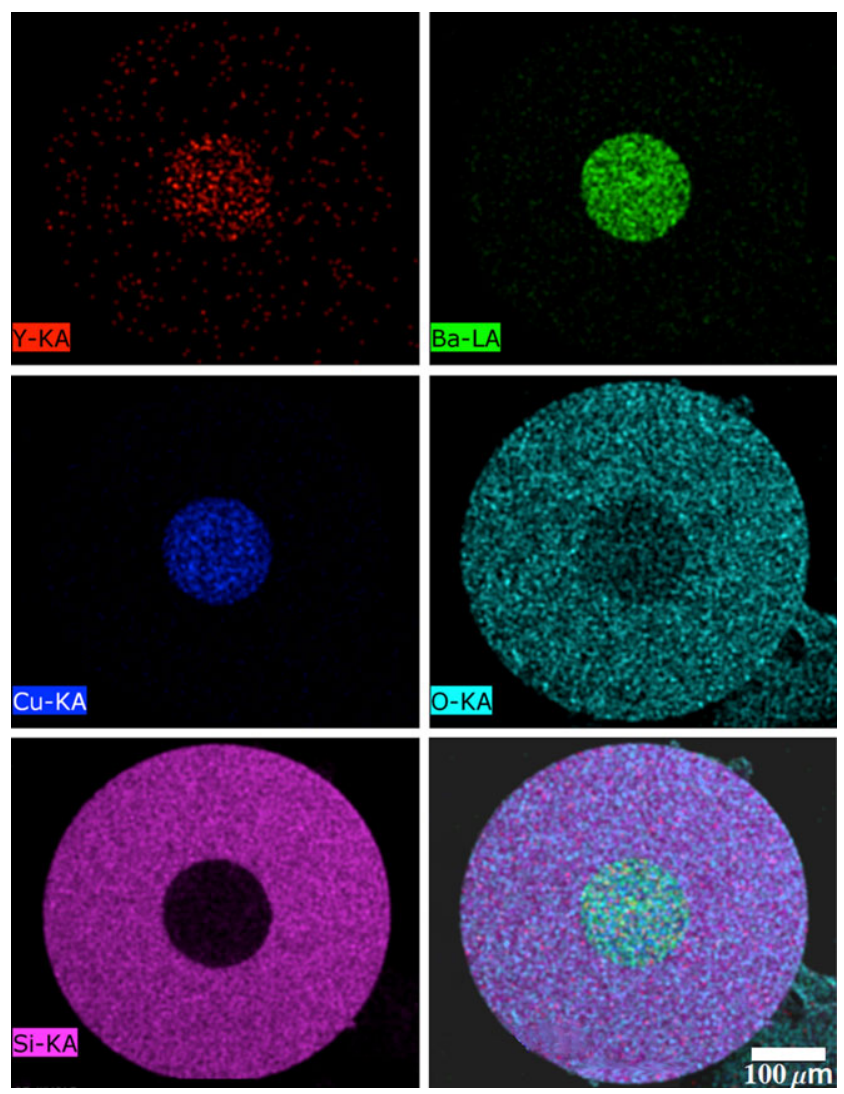

Fig. 4 X-ray dot mapping of yttrium (red), barium (green), copper (blue), oxygen (turquoise), and silicon (pink). A composite X-ray dot map image is shown in the bottom right-hand corner. There is limited cross diffusion of the elements between the core and clad, but yttrium diffusion from the core to the clad and silicon diffusion from the clad to core is evident. A well-defined elemental transition is noted at the core-clad interface region

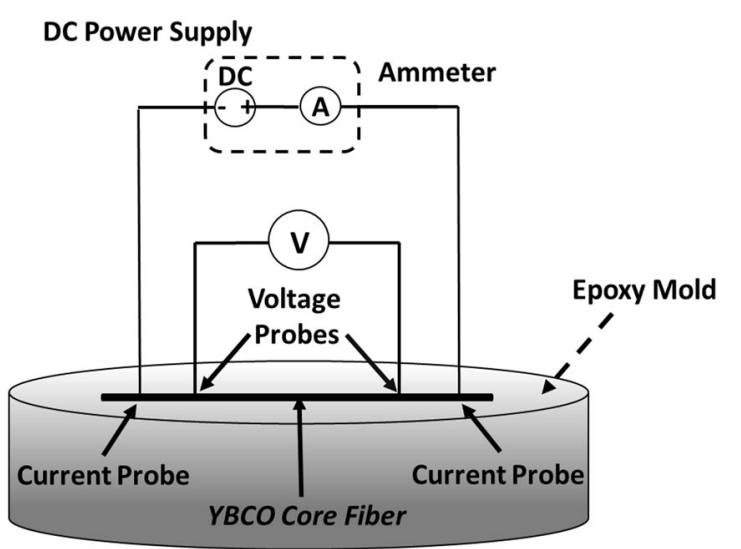

Fig. 5 Schematic of the Four-Point Probe test setup. Three samples were tested: (1) "as received" commercial brass laminated high-temperature superconducting wire, (2) a commercial bulk YBCO disk, and (3) YBCO superconducting core fiber with the fused silica clad. A custom mechanical fixture was used to assure stable contact with the superconducting material. The samples were immersed in a liquid nitrogen housed in a Styrofoam ${ }^{\mathrm{TM}}$ container. A voltage drop of approximately $1.1 \mathrm{mV}$ at $25^{\circ} \mathrm{C}$ was set for each sample by adjusting the current
The fused silica cladding could not be readily removed via hydrofluoric etching and/or mechanically because of the brittle nature of the YBCO material and necessitated the use of an alternative to expose the core. The YBCO core fiber was mounted into an epoxy resin mold and then carefully polished to expose the core in lengthwise fashion. The polished probe ends were placed in direct contact with the YBCO core with a custom test fixture to assure stable measurements. Furthermore, the probes were mounted in another mold at specific intervals of approximately $0.25 \mathrm{~mm}$. Liquid nitrogen was used for the YBCO core fiber because the critical temperature is approximately $93 \mathrm{~K}$, and the boiling point of liquid nitrogen is $77 \mathrm{~K}$. A HP Hewlett-Packard Agilent, 6633A System was utilized as the direct current supply and ammeter. An Agilent, 34405A, 5 1/2 Digit Multimeter was connected to the "voltage probes" to accurately measure the voltage drop. Both Type T and E thermocouples were utilized to continuously monitor the temperate of the sample.

A baseline measurement was performed with a commercially available brass laminated high-temperature superconducting wire (thickness $\approx 0.4 \mathrm{~mm}$, width $\approx 4.4 \mathrm{~mm}$ ) in a liquid nitrogen bath to confirm the validity of the test setup. As seen in Fig. 6(a), the resistance of the commercial superconducting wire disappeared at temperatures on the order of $93 \mathrm{~K}$. Although, the initial electrical resistance was considerably larger, the superconducting YBCO core fibers appeared to demonstrate a slightly higher $T_{\mathrm{c}}$ of approximately 95 K. As shown in Fig. 6(b), the superconducting transition was also evaluated for a commercially bulk YBCO disk (diameter $\approx 25 \mathrm{~mm}$, thickness $\approx 3.1 \mathrm{~mm}$ ) to further confirm the performance of the superconducting fiber. The transition temperature of the bulk YBCO, $T_{\mathrm{c}} \approx 93 \mathrm{~K}$, was lower than both the commercial wire and superconducting fiber. Although further investigation is required, the difference in $T_{\mathrm{c}}$ is currently attributed to measurement errors arising due the variation in thermocouple positions, thermal electromotive forces, external electromagnetic radiation, Faraday currents, and the degradation of the electrical contacts, as well as basic errors in the experimental setup [26, 27]. The critical temperature has been verified and extensively studied in the literature and is generally accepted as approximately $93 \mathrm{~K}$, which is in good agreement with the measurements in this study [28].

The demonstration of a Type II superconducting fiber is one step closer to simple and cost effective superconducting cables for long haul power transmission, sensors, and devices. High-temperature superconductivity in traditional geometries such as fibers may well provide pave the way for the significant advancement of superconductivity in the landscape of emerging technologies. 


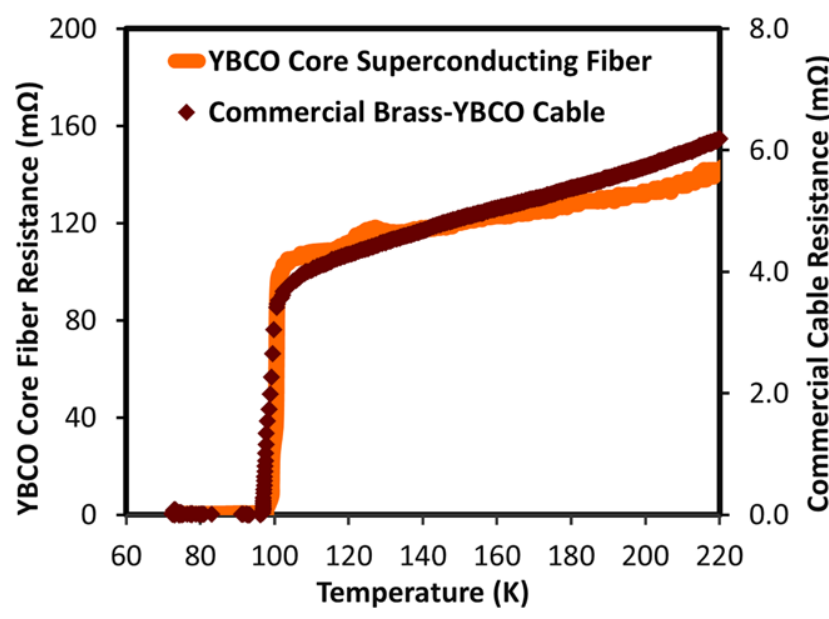

(a)

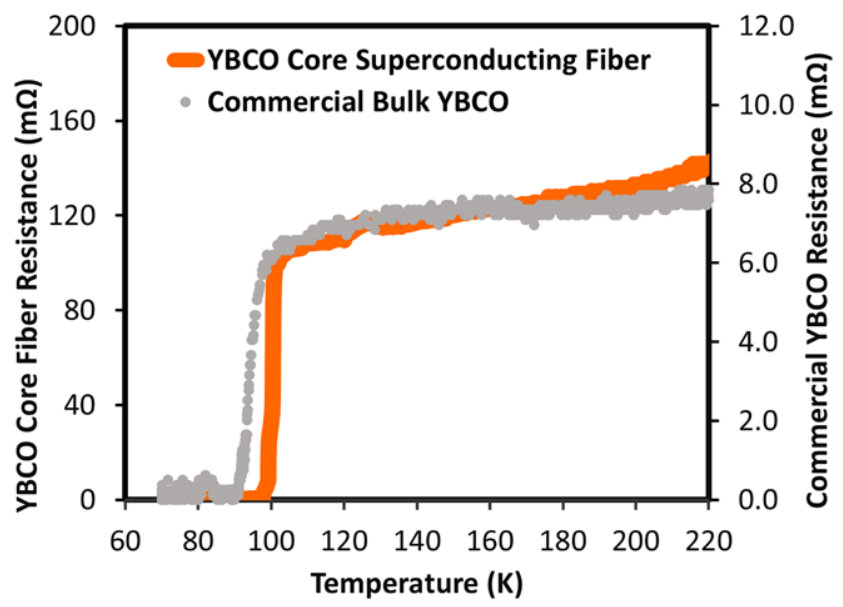

(b)

Fig. 6 Electrical resistance as a function of temperature upon full immersion in liquid nitrogen for (a) commercial brass laminated high-temperature superconducting wire and a YBCO core superconducting fiber with a fused silica clad and (b) a commercial bulk YBCO disk and a YBCO core superconducting fiber with the fused silica clad. The primary vertical axis is the resistance of the YBCO core samples, and the secondary vertical axis is the resistance of the commercial high-temperature superconducting samples. All samples maintain a critical temperature of approximately $90-100 \mathrm{~K}$

Open Access This article is distributed under the terms of the Creative Commons Attribution License which permits any use, distribution, and reproduction in any medium, provided the original author(s) and the source are credited.

\section{References}

1. Zimmerman, G.O.: Superconductivity: the promise and reality. Int. J. Mod. Phys. B 17(18-20), 3698-3701 (2003)

2. Williams, R.: APS News 20(5), 1, 4 (2011)

3. Hikami, S., Hirai, T., Kagoshima, S.: High transition temperature superconductor: Y-Ba-Cu oxide. Jpn. J. Appl. Phys. 26, L314L315 (1987)

4. Paranthaman, M.P., Izumi, T.: High-performance YBCO-coated superconductor wires. Mater. Res. Soc. Bull. 29(08), 533-541 (2004)
5. Maguire, J., Schmidt, F., Bratt, S., Welsh, T., Yuan, J., Allais, A., Hamber, F.: Development and demonstration of a HTS power cable to operate in the long island power authority transmission grid. IEEE Trans. Appl. Supercond. 17(2), 2034-2037 (2007)

6. Chen, M., Donzel, L., Lakner, M., Paul, W.: High temperature superconductors for power applications. J. Eur. Ceram. Soc. 24(6), 1815-1822 (2004)

7. Sazio, P.J., Amezcua-Correa, A., Finlayson, C.E., Hayes, J.R., Scheidemantel, T.J., Baril, N.F., Jackson, B.R., Won, D.-J., Zhang, F., Margine, E.R.: Microstructured optical fibers as high-pressure microfluidic reactors. Science 311(5767), 1583-1586 (2006)

8. Ballato, J., Hawkins, T., Foy, P., Yazgan-Kokuoz, B., McMillen, C., Burka, L., Morris, S., Stolen, R., Rice, R.: Advancements in semiconductor core optical fiber. Opt. Fiber Technol. 16(6), 399 $408(2010)$

9. Scott, B., Wang, K., Caluori, V., Pickrell, G.: Fabrication of silicon optical fiber. Opt. Eng. 48(10), 100501 (2009)

10. Homa, D., Liang, Y., Pickrell, G.: Superconducting fiber. Appl. Phys. Lett. 103(8), 082601 (2013)

11. Pickrell, G.R., Smirnova, E.: Novel structures in random hole optical fibers. In: IEEE Sensors (2005). 4 pp

12. Ballato, J., Hawkins, T., Foy, P., McMillen, C., Burka, L., Reppert, J., Podila, R., Rao, A., Rice, R.R.: Binary III-V semiconductor core optical fiber. Opt. Express 18(5), 4972-4979 (2010)

13. Scott, B.L., Wang, K., Pickrell, G.: Fabrication of n-type silicon optical fibers. IEEE Photonics Technol. Lett. 21(24), 1798-1800 (2009)

14. Taylor, G.: A method of drawing metallic filaments and a discussion of their properties and uses. Phys. Rev. 23(5), 655 (1924)

15. Grodkiewicz, W.: Fused silica fibers with metal cores. Mater. Res. Bull. 10(10), 1085-1090 (1975)

16. Lian, Z., Pingxiang, Z., Ping, J., Keguang, W., Jingrong, W., Xiaozu, W.: The properties of YBCO superconductors prepared by a new approach: the 'powder melting process'. Supercond. Sci. Technol. 3(10), 490 (1990)

17. Jin, S., Tiefel, T., Sherwood, R., Kammlott, G., Zahurak, S.: Fabrication of dense $\mathrm{Ba}_{2} \mathrm{YCu}_{3} \mathrm{O}_{7-\delta}$ superconductor wire by molten oxide processing. Appl. Phys. Lett. 51(12), 943-945 (1987)

18. Müller, P., Schubert, M., Rodig, C., Fuchs, G., Fischer, K.: Heat treatment of wires on the basis of the high $T$ superconductor YBaCuO. Appl. Phys. Lett. 55, 917 (1989)

19. Jee, Y., Kim, C., Sung, T., Hong, G.: Top-seeded melt growth of $\mathrm{Y}-\mathrm{Ba}-\mathrm{Cu}-\mathrm{O}$ superconductor with multiseeding. Supercond. Sci. Technol. 13(2), 195 (2000)

20. Donald, I., Metcalfe, B.: The preparation, properties and applications of some glass-coated metal filaments prepared by the Taylorwire process. J. Mater. Sci. 31(5), 1139-1149 (1996)

21. Pardoe, G., Butler, E., Gelder, D.: Rapid quenching by the Taylor wire technique. J. Mater. Sci. 13(4), 786-790 (1978)

22. Butler, I., Kurz, W., Gillot, J., Lux, B.: The production of metal fibres and wires directly from the melt. Fibre Sci. Technol. 5(4), 243-262 (1972)

23. Zhukov, A., González, J., Blanco, J., Vazquez, M., Larin, V.: Microwires coated by glass: a new family of soft and hard magnetic materials. J. Mater. Res. 15(10), 2107-2113 (2000)

24. Bayindir, M., Abouraddy, A.F., Shapira, O., Viens, J., SayginHinczewski, D., Sorin, F., Arnold, J., Joannopoulos, J.D., Fink, Y.: Kilometer-long ordered nanophotonic devices by preform-to-fiber fabrication. IEEE J. Sel. Top. Quantum Electron. 12(6), 12021213 (2006)

25. Vazquez, V., Pérez-Amaro, N., Canizo-Cabrera, A.: Selected error sources in resistance measurements on superconductors. Rev. Sci. Instrum. 72(8), 3332-3339 (2001) 
26. Cohen, M., Falicov, L., Phillips, J.: Superconductive tunneling. Phys. Rev. Lett. 8(8), 316-318 (1962)

27. Hua, J., Xiao, Z., Rosenmann, D., Beloborodov, I., Welp, U., Kwok, W., Crabtree, G.: Resistance anomaly in disordered superconducting films. Appl. Phys. Lett. 90(7), 072507 (2007)
28. Genoud, J.-Y., Graf, T., Junod, A., Sanchez, D., Triscone, G., Muller, J.: Preparation, resistivity, magnetic properties and specific heat of the $95 \mathrm{~K}$ superconductor $\mathrm{YBa}_{2} \mathrm{Cu}_{3.5} \mathrm{O}_{7.5+x}$ (“247”). Physica C, Supercond. 177(4), 315-329 (1991) 